\title{
Outbreak of Rift Valley fever affecting veterinarians and farmers in South Africa, 2008
}

\author{
Brett N Archer, Jacqueline Weyer, Janusz Paweska, Deliwe Nkosi, Patricia Leman, Khin San Tint, Lucille Blumberg
}

Background. During 2008, Rift Valley fever (RVF) virus re-emerged in South Africa as focal outbreaks in several provinces.

Aims. To investigate an outbreak affecting cattle farmers and farm workers, and the staff and students of a veterinary school, assess the prevalence of infection during the outbreak, document the clinical presentation of cases, and identify potential risk factors.

Methods. We conducted a cross-sectional serological survey of exposed veterinarians and farmers, who were examined to determine the presence of current or recent illness. Blood specimens were collected for virus isolation, nucleic acid detection and serology. A subset was interviewed using a standardised questionnaire to obtain data on recent exposures and risk factors for infection.

Results. Of 53 participants potentially exposed to infected domestic ruminants, $15 \%$ had evidence of recent infection and $4 \%$ evidence of past exposure to the RVF virus. The prevalence of acute infection was $21 \%$ in veterinarians compared with $9 \%$ in farmers and farm workers. After a mean incubation period of 4.3 days, the most frequent symptoms experienced included myalgia (100\%), headache $(88 \%)$ and malaise $(75 \%)$. No asymptomatic cases were identified. Transmission by direct contact with infected animals was the major risk factor in these professional groups. Performing animal autopsies was significantly associated with acute infection (risk ratio 16.3, 95\% confidence interval 2.3 - 114.2).

Conclusions. Increased risks associated with veterinary practices highlight a need for the use of personal protective equipment, and identify veterinarians as a primary target group for future vaccination.

S Afr Med J 2011;101:263-266
Rift Valley fever (RVF) is a viral zoonosis endemic to Africa ${ }^{1}$ that primarily affects domestic ruminants, causing large epizootics with high mortality rates in young animals and abortions. ${ }^{1-3}$ Transmission to humans occurs through direct contact with infected animal tissues, blood or other body fluids, and less commonly by mosquito bites. Inhalation of aerosolised infected fluids or ingestion of unpasteurised milk from infected animals might also be less frequent sources of infection. ${ }^{4-5}$ Since contact with sick animals and animal products, including blood, meat and milk, is the major risk factor for acquiring RVF, occupational groups such as farmers, slaughterhouse workers and veterinarians are at an increased risk of infection. ${ }^{4,6-8}$ No humanto-human transmission has been documented.

Infection in humans is typically asymptomatic or limited to a mild febrile illness. Complications are rare, but may manifest as

Outbreak Response Unit, National Institute for Communicable Diseases (NICD) of the National Health Laboratory Service (NHLS), Sandringham, Johannesburg, and South African Field Epidemiology and Laboratory Training Programme (SA-FELTP), NICD-NHLS and School of Health Systems and Public Health, University of Pretoria Brett N Archer, MPH, PGCertPH, BMedSc

Special Pathogens Unit, NICD-NHLS

Jacqueline Weyer, $\mathrm{PhD}$

Janusz Paweska, DVSc, Dr hab, Prof Vet Sci

Patricia Leman, BSc Hons

SA-FELTP, NICD-NHLS and School of Health Systems and Public Health, University of Pretoria

Deliwe Nkosi, MB ChB, BRad (Diag)

Khin San Tint, MB BS, MMedSc (P\&TM), MPH

Epidemiology Division, NICD-NHLS

Lucille Blumberg, MB BCh, MMed (Clin Micro), Cert ID (SA), FFTM RCPS

(Glasg), DOH, DTM\&H, DCH encephalitis $(1-10 \%)$, hepatitis $(<1 \%)$, haemorrhagic fever $(<1 \%)$ or retinitis $(<1 \%) .{ }^{5}$ Deaths due to RVF virus (RVFV) infections are rare (case fatality rate $1 \%) .{ }^{5}$ Long-lasting immunity follows infection, making RVFV a good candidate for prevention by vaccine, which may be expected for wider use in the near future. ${ }^{9}$ In the past, highrisk occupational groups in South Africa could receive an unlicensed, inactivated whole-virus vaccine against RVF. ${ }^{10}$ However, vaccination of cattle and other ruminants is encouraged using licensed RVF vaccines for veterinary use.

Sporadic outbreaks of RVF have been recorded in South Africa over the past five decades, the last major epidemic having been between 1974 and 1976..$^{3-4}$ The 1977 RVF epidemic in Egypt resulted in an estimated $20-30 \%$ attack rate in this completely susceptible human population. ${ }^{11}$ Outbreaks have been reported in sub-Saharan Africa, North Africa, the Arabian Peninsula, the Comoros, Kenya, Somalia, the United Republic of Tanzania, Mayotte, Madagascar, Saudi Arabia and Yemen from 1997 to 2008., ${ }^{512-20}$

During 2008 a re-emergence of RVF in South Africa was observed, with several focal outbreaks affecting livestock and humans across five provinces (Eastern Cape, Gauteng, Limpopo, Mpumalanga and North West). RVFV infection was confirmed in animals by the Agriculture Research Council-Onderstepoort Veterinary Institute (ARC-OVI) and the University of Pretoria. We report the subsequent outbreak of RVF in dairy farmers and farm workers, and the staff and students of a veterinary school. We investigated the prevalence of RVFV infection among them, their clinical presentation, and the risk factors associated with infection.

\section{Methods}

We conducted a cross-sectional serological survey of the exposed staff complement of farmers and farm workers from dairy farms with confirmed RVF in animals, and veterinary school staff and students exposed to carcasses and tissues of infected animals. Participants were examined to determine the presence of current or recent illness with symptoms compatible with RVFV infection. The suspect case definition included any person presenting with influenza-like illness (including fever $\geq 38^{\circ} \mathrm{C}$, myalgia or headache), or any illness with 
features of fever with encephalitis, haemorrhage, hepatitis or ocular pathology, with onset of illness after the date of exposure to the affected animals.

Blood specimens were collected from all participants regardless of illness status for laboratory analysis by the National Institute for Communicable Diseases (NICD) of the National Health Laboratory Service (NHLS). To differentiate acute infection, non-infected, and persons with a past immunising event (previous infection or vaccination), RVF IgG and IgM enzyme-linked immunosorbent assay (ELISA) were performed. ${ }^{21}$ Additional tests included nucleic acid detection (an RVFV real-time reverse transcription polymerase chain reaction (PCR) and/or loop-mediated isothermal amplification assay) and/or virus isolation..$^{22}$ A confirmed case was defined as any individual with a positive IgM, nucleic acid detection and/ or virus isolation result. Blood specimens were collected from hospitalised patients, analysed by a private pathology service to measure liver function, enzyme, protein and haematology levels and compared against standard haematology and biochemistry reference intervals. $^{23}$

A subset of the two occupational groups was interviewed using a standardised questionnaire for data on recent exposures and risk factors for infection. This included all participants meeting the confirmed case definition (acute infection), and a convenience sample of exposed individuals without documented illness (non-infected), excluding individuals with a laboratory-proven past immunising event, from the same occupational group. Data from completed questionnaires and laboratory results were captured and analysed using Epi Info 2000 (version 3.5.1, Centers for Disease Control and Prevention, Atlanta). Risk ratios (RRs) were calculated to compare infected and non-infected cases, and a chi-square test was performed with $p$-values $<0.05$ considered significant.

Ethics clearance for essential communicable disease surveillance was granted to the NICD by the Human Medical Research Ethics Committee of the University of the Witwatersrand, Johannesburg (protocol number M060449, reference R14/49 Schoub). This includes outbreak investigations related to notifiable medical conditions under surveillance, including RVF.

\section{Results}

A total of 53 participants from the exposed groups were surveyed, including a complete staff complement of 22 dairy farm workers and 31 veterinary school staff and students. Of these, $30 \%\left(\mathrm{n}_{\text {farm }}=7\right.$ and $n_{\text {school }}=9$ ) met the suspect case defection - presenting with illness compatible with RVFV infection. Of 53 blood specimens, $15 \%\left(\mathrm{n}_{\text {farm }}=2\right.$ and $\left.\mathrm{n}_{\text {school }}=6\right)$ were confirmed as having an acute RVFV infection. In $4 \%\left(\mathrm{n}_{\text {school }}=2\right)$, anti-RVFV IgG was detected in the absence of anti-RVFV IgM; they were therefore classified as previously immunised, but we could not determine whether this was due to prior RVFV exposure or vaccination. Excluding the nonsusceptible individuals, the attack rate of RVFV infection was $16 \%$ $(8 / 51)$ in the total population surveyed, $9 \%(2 / 22)$ in the dairy farm group, and $21 \%(6 / 29)$ in the veterinary school group.

Of the 8 laboratory-confirmed cases, 4 were aged 20 - 29 years and 5 were male; 4 were diagnosed by detection of anti-RVFV IgM alone, 3 by PCR and virus isolation, and 1 by PCR alone. Onset of illness of the two farmers was 2 and 8 days respectively after contact with sick or dead calves; however, timing of exposure may have varied (Fig. 1). The date of conducting the animal autopsies, and therefore exposure, was known for the veterinary school group and a mean incubation period of 4.3 days (range 4 - 5 days) could be calculated.

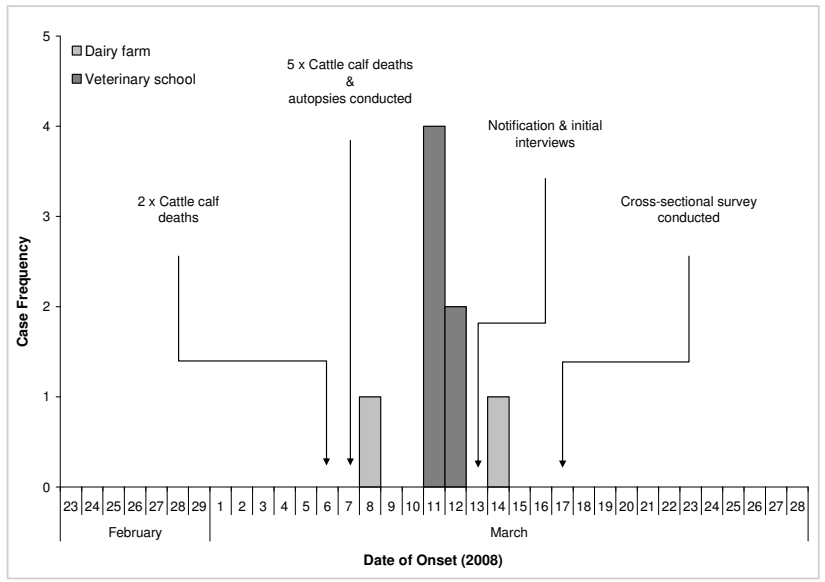

Fig. 1. Epidemic curve illustrating the frequency of confirmed Rift Valley fever cases by date of illness onset, dates of cattle deaths and exposure, and dates of investigation, Rift Valley fever outbreak, South Africa, 2008.

All participants with laboratory evidence of recent viral infection were symptomatic and met the suspect case definition criteria. The most frequently reported symptoms included myalgia $(8 / 8$, $100 \%)$, headache $(7 / 8,88 \%)$ and malaise $(6 / 8,75 \%)$, and $63 \%$ $(5 / 8)$ were pyrexial (Table I). Four $(50 \%)$ of the confirmed cases required hospitalisation, and RVF-associated encephalitis developed in 1 patient (13\%) approximately a week after the acute episode. The immunological response of the 4 hospitalised cases, measured during the acute episode (Table II), showed raised levels of C-reactive protein (CRP), aspartate transaminase (AST) and alanine transminase (ALT). Three of the 4 patients had raised neutrophil granulocytes and decreased lymphocyte counts. Total white blood cell and platelet counts were normal among all 4 patients.

The 8 confirmed cases and an additional 22 susceptible, nonimmune individuals from the two groups were interviewed. All confirmed cases had direct contact with either sick or dead cattle (Table III), and there was a statistically significant association between performing an animal autopsy and acute infection (RR 16.3, $95 \%$ confidence interval 2.3 - 114.2). None of the other risk factors considered were significant.

Table I. Frequency of symptoms and signs among 8 patients with confirmed Rift Valley fever virus infection in South Africa, 2008

\begin{tabular}{lc}
\hline Symptom & Frequency $(N(\%))$ \\
\hline Myalgia & $8(100)$ \\
Headache & $7(88)$ \\
Malaise & $6(75)$ \\
Pyrexia $\left(>38^{\circ} \mathrm{C}\right)$ & $5(63)$ \\
Nausea & $5(63)$ \\
Dizziness & $5(63)$ \\
Abdominal pain & $3(38)$ \\
Rigors & $3(38)$ \\
Vomiting & $2(25)$ \\
Hyperaesthesia & $1(13)$ \\
Diarrhoea & $0(0)$ \\
\hline
\end{tabular}


Table II. Measured liver function and haematological values and enzyme and protein levels in blood specimens from 4 hospitalised confirmed Rift Valley fever cases during acute-stage infection: Rift Valley fever outbreak, South Africa, 2008

\begin{tabular}{|c|c|c|c|c|c|}
\hline & \multirow[b]{2}{*}{ Reference intervals $^{\dagger}$} & \multicolumn{4}{|c|}{ RVF cases } \\
\hline & & A & $\mathrm{B}$ & $\mathrm{C}$ & $\mathrm{D}$ \\
\hline C-reactive protein $(\mathrm{mg} / \mathrm{l})$ & $<8$ & 36 & 46.1 & 45.6 & - \\
\hline Aspartate transaminase (IU/l) & $3-35$ & 107 & 93 & 94 & 82 \\
\hline Alanine transminase (IU/l) & $3-35$ & 62 & 141 & 80 & 67 \\
\hline Total white blood cell count (WCC) $\left(\times 10^{9} / 1\right)$ & $4-11$ & 5.31 & 3.72 & 5.25 & 2.51 \\
\hline Neutrophil granulocytes (\% WCC) & $40-75$ & 81 & 78.7 & 91.4 & 62 \\
\hline Lymphocyte (\% WCC) & $20-45$ & 8.5 & 10.9 & 5.6 & 25 \\
\hline Platelet count $\left(\times 10^{9} / \mathrm{l}\right)$ & $150-400$ & 214 & 157 & 226 & 140 \\
\hline Total/direct bilirubin $(\mu \mathrm{mol} / \mathrm{l})$ & $3-17 / 1.7-5.1$ & $15 / 2$ & $22 / 5$ & $28 / 3$ & - \\
\hline
\end{tabular}

Table III. Analysis of risk factors among exposed populations during an outbreak of Rift Valley fever in South Africa, 2008

\begin{tabular}{|c|c|c|c|c|}
\hline Exposure/risk factor & $\begin{array}{l}\text { Confirmed acute cases, } \\
N=8(N(\%))\end{array}$ & $\begin{array}{l}\text { Non-infected, } \\
N=22(N(\%))\end{array}$ & $\mathrm{RR}$ & $95 \%$ CI \\
\hline Direct contact with sick/dead cattle & $8(100)$ & $6(27)$ & - & - \\
\hline Performed autopsy & $7(88)$ & $2(9)$ & 16.3 & $2.3-114.2$ \\
\hline Disposed of carcass & $4(50)$ & $8(36)$ & 1.5 & $0.5-4.9$ \\
\hline Slaughtered an animal & $1(13)$ & $3(14)$ & 0.9 & $0.2-5.7$ \\
\hline Disposed of aborted fetus & $2(25)$ & $7(32)$ & 0.8 & $0.2-3.1$ \\
\hline Handled raw meat & $1(13)$ & $11(50)$ & 0.2 & $<0.1-1.5$ \\
\hline Skinned an animal & $0(0)$ & $2(9)$ & - & - \\
\hline Consumed unpasteurised milk & $0(0)$ & $0(0)$ & - & - \\
\hline Consumed raw meat & $0(0)$ & $0(0)$ & - & - \\
\hline $\mathrm{RR}=$ risk ratio $\mathrm{CI}=$ confidence interval. & & & & \\
\hline
\end{tabular}

\section{Discussion}

We documented an occupationally linked outbreak of RVF in farming and veterinary professionals coinciding with the re-emergence of RVF in South Africa after an extended inter-epizootic period. The 8 confirmed human cases in the two occupational groups surveyed suggest that exposure to either sick or dead cattle was the major route of transmission. We noted an elevated attack rate and a significantly increased risk of infection among veterinarians who performed autopsies. Inadequate use of personal protective equipment, and use of high-pressure water jets to clean equipment and surfaces during animal autopsies, may have contributed to an increased risk among veterinarians by direct contact with infected tissues, or exposure to infectious aerosolised body fluids.

After a mean incubation period of 4.3 days, confirmed cases presented with symptoms of myalgia, headache and malaise. Pyrexia was documented in roughly half of the patients; however, this may be understated owing to late measurement of body temperature in nonhospitalised patients. Haematological and biochemical investigations on hospitalised patients all showed raised levels of CRP, AST and ALT, indicating inflammation and acute liver damage in more severely ill patients. Serological investigations revealed an additional 2 participants with a previous immunising event; however, no asymptomatic acute infections were found, in contrast to the common occurrence of asymptomatic infection observed elsewhere. ${ }^{5}$

Our findings, and specifically the risk factor analysis, may be limited in power by the few study participants. Secondly, demographic characteristics were not available for the proportion of the surveyed population excluded from in-depth interviews (non-respondents), prohibiting comparisons with the respondent group to exclude differences that may introduce bias.

Despite these limitations, this epizootic highlights the need for renewed vaccinations of ruminants against RVFV in South Africa. Increased risks of infection associated with veterinary practices emphasise the need for improved use of personal protective equipment and other preventive measures, especially while performing animal autopsies. This occupational group should also be considered as a primary target for future immunisation against RVF once human vaccines become available. Further strengthening of surveillance and intersectoral collaboration between the health and agriculture sectors will assist in rapid recognition and response to future outbreaks.

The authors acknowledge members of the Outbreak Response Unit, the South African Field Epidemiology and Laboratory Training Programme (SA-FELTP), and the technical team of the Special Pathogens Unit, 


\section{Original ArTiCles}

NICD-NHLS; public health registrars at the University of Witwatersrand; the Department of Veterinary Tropical Diseases, University of Pretoria, and ARC-OVI (for providing results of animal testing and participating in the outbreak investigation); Lancet Laboratories (for supplying haematological and biochemical data on hospitalised patients); and the South African Department of Health and the Department of Agriculture, Forestry, and Fisheries.

The authors have no conflict of interests to declare.

References

1. Pepin M, Bouloy M, Bird BH, Kemp A, Paweska J. Rift Valley fever virus (Bunyaviridae: Phlebovirus): an update on pathogenesis, molecular epidemiology, vectors, diagnostics and prevention. Vet Res $2010 ; 41(6): 61$ Joubert JD, Ferguson AL, Gear J. Rift Valley fever in South Africa: 2. The occurrence of human cases . Joubert JD, Ferguson AL, Gear J. Rift Valley fever in South Africa: 2. The occurrence of human cases Epidemiological and clinical findings. S Afr Med J 1951;25(48):890-891.

Epidemiological and clinical findings. S Afr Med J 1951;25(48):890-891.
McIntosh BM, Russell D, dos Santos I. Gear JH. Rift Valley fever in humans in South Africa. S Afr Med 3. McIntosh BM, Russell

J 1980;58(20):803-806.
4. Swanepoel R, Coetzer J. Rift Valley fever. In: Coetzer J, Tustin R, eds. Infectious Diseases of Livestock.

4. Swanepoel R, Coetzer J. Rift Valley fever. In: Coetzer J, Tustin
2nd ed. New York: Oxford University Press, 2004: 1037-1059.

Rift Valley fever fact sheet. Wkly Epidemiol Rec 2008;83(2):17-22

6. Abu-Elyazeed R, el-Sharkawy S, Olson J, et al. Prevalence of anti-Rift-Valley-fever IgM antibody in abattoir workers in the Nile delta during the 1993 outbreak in Egypt. Bull World Health Organ 1996;74(2):155-158.

. Mundel B, Gear J. Rift valley fever: I. The occurrence of human cases in Johannesburg. S Afr Med J 1951;25(44):797-800

8. Swai ES, Schoonman L. Prevalence of Rift Valley fever immunoglobulin G antibody in various occupational groups before the 2007 outbreak in Tanzania. Vector Borne Zoonotic Dis 2009;9(6):579-582.
9. Ikegami T, Makino S. Rift valley fever vaccines. Vaccine 2009:27(Suppl 4):D69-72.

10. Pittman PR, Liu CT Cannon TL, et al. Immunogenicity of an inactivated Rift Valley fever vaccine in humans: a 12-year experience. Vaccine 1999;18(1-2):181-189.

11. El-Akkad AM. Rift Valley fever outbreak in Egypt. October - December 1977. J Egypt Public Health Assoc 1978:53(3-4):123-128.

12. Bird BH, Ksiazek TG, Nichol ST, Maclachlan NJ. Rift Valley fever virus. J Am Vet Med Assoc 2009;234(7):883-893.

13. Outbreak news. Rift Valley fever, Madagascar. Wkly Epidemiol Rec 2008;83(18):157.

14. Clements AC, Pfeiffer DU, Martin V, Otte MJ. A Rift Valley fever atlas for Africa. Prev Vet Med 2007;82(1-2):72-82

Outbreaks of Rift Valley fever in Kenya, Somalia and United Republic of Tanzania, December 2006 April 2007. Wkly Epidemiol Rec 2007;82(20):169-178.

16. Rift Valley fever outbreak - Kenya, November 2006 - January 2007. MMWR Morb Mortal Wkly Rep 2007;56(4):73-76

7. Madani TA Al-Mazrou $\mathrm{YY}$ Al-Jeffi $\mathrm{MH}$, et al Rift Valley fever epidemic in Saudi Arabia epidemiological, clinical, and laboratory characteristics. Clin Infect Dis 2003;37(8):1084-1092.

Woods CW, Karpati AM, Grein T, et al. An outbreak of Rift Valley fever in Northeastern Kenya, 199798. Emerg Infect Dis 2002;8(2):138-144.

19. Mohamed M, Mosha F, Mghamba J, et al. Epidemiologic and clinical aspects of a Rift Valley fever Mohamed M, Mosha F, Mghamba J, et al. Epidemiologic and clinical aspects of a
outbreak in humans in Tanzania, 2007. Am J Trop Med Hyg 2010;83(2 Suppl):22-27.

20. Andriamandimby SF, Randrianarivo-Solofoniaina AE, Jeanmaire EM, et al. Rift Valley fever during rainy seasons, Madagascar, 2008 and 2009. Emerg Infect Dis 2010;16(6):963-970.

1. Paweska JT, Burt FJ, Swanepoel R. Validation of IgG-sandwich and IgM-capture ELISA for the detection of antibody to Rift Valley fever virus in humans. J Virol Methods 2005;124(1-2):173-181.

22. Le Roux CA, Kubo T, Grobbelaar AA, et al. Development and evaluation of a real-time reverse transcription-loop-mediated isothermal amplification assay for rapid detection of Rift Valley fever virus in clinical specimens. J Clin Microbiol 2009;47(3):645-651

23. Longmore M, Wilkinson I, Turmezei T, Cheung C. Oxford Handbook of Clinical Medicine. 7th ed. Oxford: Oxford University Press, 2007.

Accepted 17 November 2010

\section{Are you a doctor, nurse or pharmacist? Do you need clinical assistance with the treatment of your HIV or TB patients?}

Contact the TOLL-FREE National HIV \& TB Health Care Worker Hotline 0800212 506/021 4066782

Alternatively send an SMS or 'Please Call Me' to 0718401572

www.hivhotline.uct.ac.za

Call us - we will gladly assist you! This service is free.

The Medicines Information Centre (MIC), situated within the Division of Clinical Pharmacology, Department of Medicine, University of Cape Town, is the largest and only clinically based medicine information centre in South Africa.

In collaboration with the Foundation for Professional Development and USAID/PEPFAR, the MIC provides a toll-free national HIV and TB hotline to all health care workers in South Africa for patient treatment-related enquiries. 